http://jmscr.igmpublication.org/home/ ISSN (e)-2347-176x ISSN (p) 2455-0450 crossref DOI: https://dx.doi.org/10.18535/jmscr/v8i6.74

\title{
Poorly differentiated urothelial carcinoma of ureter presenting as Bulbar Palsy-An unusual presentation
}

\author{
Authors \\ Dr Girish V Hiregoudar ${ }^{1}$, Dr Ashok Bhupali ${ }^{2}$, Dr Archana Patil ${ }^{3}$, \\ Dr Shivkumar Donagaon ${ }^{4}$, Dr Archana Shinde ${ }^{5}$ \\ ${ }^{1}$ Consultant Physician, Apple Saraswati Multispeciality Hospital, Kolhapur \\ ${ }^{2}$ Consultant Cardiologist, Apple Saraswati Multispeciality Hospital, Kolhapur \\ ${ }^{3,4}$ Consultant Radiologist, Apple Saraswati Multispeciality Hospital, Kolhapur \\ ${ }^{5}$ Consultant Pathologist, Apple Saraswati Multispeciality Hospital, Kolhapur
}

\section{Summary}

Urothelial neoplasms of the kidney and ureter (upper urinary tract) are uncommon, accounting for approximately 5\% of all epithelial tumors of the urinary tract, with most urothelial tumors occurring in the urinary bladder ${ }^{1-8}$. Patients with upper tract urothelial neoplasms usually seek care because of gross hematuria (80\%), flank pain (20\%), and/or a palpable mass (10\%).,15,16. Here,we present a case of poorly differentiated urothelial carcinoma from upper ureter with a unique presentation with bulbar palsy.

\section{Case Report}

A 55 years old Female patient presented with $\mathrm{H} / \mathrm{O}$ low back ache since 6 months, difficulty in swallowing both for liquids and solids since 1 month.

On examination- she was found to have left $9^{\text {th }}$ to $12^{\text {th }}$ cranial nerve palsies. She was admitted and evaluated for bulbar palsy. Her MRI brain revealed a fairly well defined altered intramedullary signal involving the clivus on the left with mild expansion of bone - features suspicious for metastasis.

Hence patient was evaluated to search for the primary with CECT abdomen and chest which revealed possibility of neoplastic lesion in the left upper ureter (? TCC) with retroperitoneal adenopathy, hepatic \& skeletal metastasis. Well defined lobulated intense heterogeneously enhancing hypodense lesion in the left paratracheal region extending superiorly into the lower neck.

Excision biopsy of the paratracheal lesion revealed poorly differentiated carcinoma.IHC of the sample revealed metastatic poorly differentiated urothelial carcinoma.

This was unique presentation where poorly differentiated urothelial carcinoma presented as bulbar palsy.

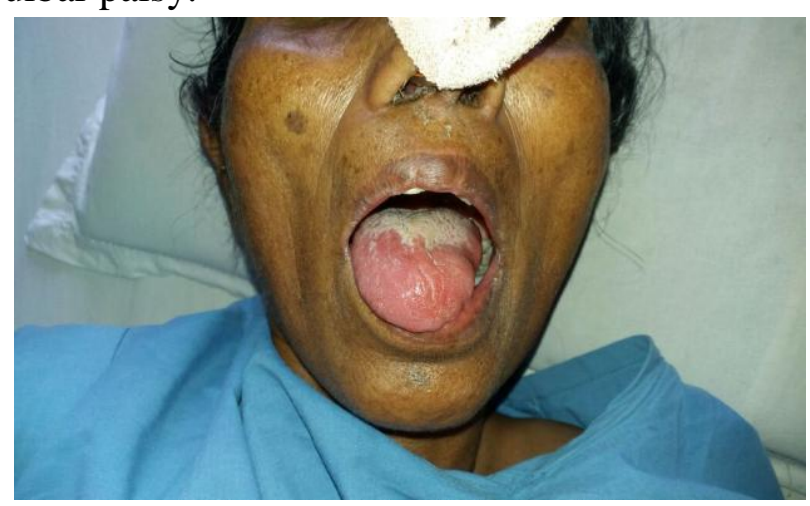

Fig.1 Left hypoglossal weakness 


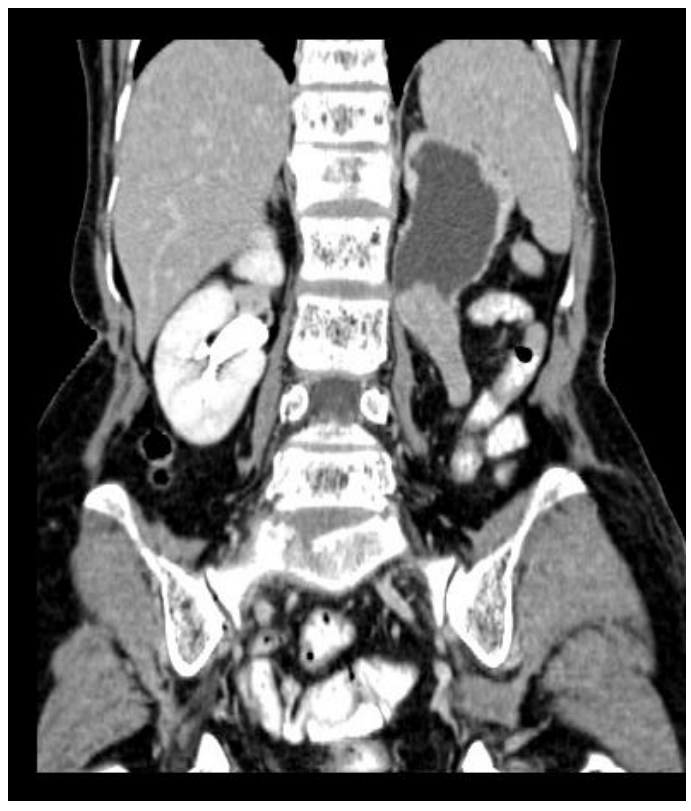

Fig.2 CT Abdomen-left Ureteric mass with hydronephrosis and vertebral metastasis

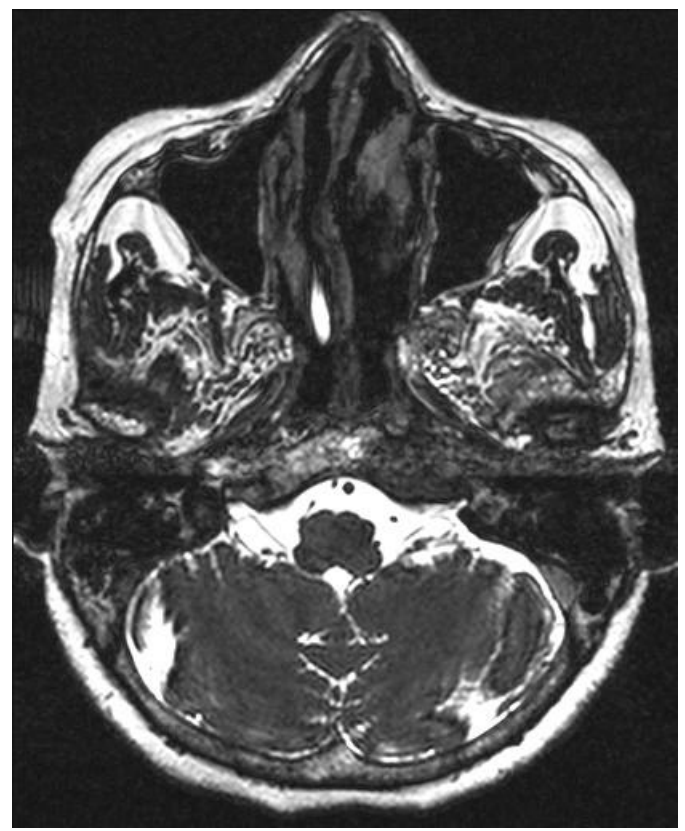

Fig.3 MRI Brain-Metastasis to clivus on left side

\section{Discussion}

Urothelial neoplasms of the kidney and ureter (upper urinary tract) are uncommon, accounting for approximately $5 \%$ of all epithelial tumors of the urinary tract, with most urothelial tumors occurring in the urinary bladder ${ }^{1-8 .}$

Nevertheless, urothelial tumors of the renal pelvicalyceal system are rare and are thought to account for $4 \%$ to $15 \%$ of primary kidney neoplasms in the United States. ${ }^{1,3-6,9-12}$
Ureteral tumors are even less common, representing $1 \%$ of all urothelial tumors. ${ }^{1,10,13,14}$

\section{Epidemiology and Risk Factors}

Most studies have found urothelial neoplasms of the kidney and ureter to be more common in men than in women. ${ }^{1-3,5-7,9-17 .}$

These tumors peak in the six and seventh decades of life, with a mean age at initial diagnosis of about 65 years, and appear to affect whites more often than other races in the United States. $5,9,12$

Urothelial neoplasms are more common in the renal pelvises and calyces than in the ureters. $1,10,13,17,20-22$

No definitive predilection for involvement of the right or left side has been found, and fewer than $3 \%$ are synchronous and bilateral. ${ }^{9,12,16,23,24}$

Many of the risk factors for developing urothelial neoplasms of the upper tract are similar to those of the bladder and include cigarette smoking, ${ }^{4,17,25}$ exposure to industrial chemicals (dye, petroleum, rubber, and leather industries), ${ }^{4,15,17}$ and chronic irritation (stones and infection). ${ }^{7,26,27}$

Exposure to radiographic contrast agents that contain thorium has also been associated with the development of upper tract tumors. ${ }^{17}$

Patients with various forms of tubulointerstitial nephritides are also at greater risk for developing urothelial neoplasms of the renal pelvis, as are people in certain regions of the world.

Analgesic nephropathy, which develops secondary to abuse of phenacetin-containing analgesics, is associated with renal papillary necrosis, capillarosclerosis (increased basement membrane around subepithelial capillaries), and urothelial neoplasms. ${ }^{17}$

In regions where phenacetin abuse is high, urothelial neoplasms represent up to $24 \%$ of kidney neoplasms. Unlike most patients with urothelial neoplasms of the renal pelvis, the male/female ratio is lower

for analgesic-related tumors, and the mean age at diagnosis is about 5 years earlier.

Patients with endemic nephropathy, described in the Balkan countries (Romania and Bulgaria and 
[the former]Yugoslavia), have a high frequency of upper tract urothelial neoplasms. Patients are most commonly diagnosed between the third and fifth decades of life, and the incidence of bilateral tumors is approximately $10 \%$.

Renal failure, which is often the cause of death, develops in most patients.

The exact cause of the disease is unknown, but it is postulated to be silicates in the drinking water.

A fairly recently described nephropathy, Chineseherb nephropathy, has been linked to the development of urinary tract neoplasms, particularly in the upper tract. This disease originally was described in Belgian women who were enrolled in a "slimming clinic." The cause of the nephropathy is the ingestion of various agents, including Chinese herbs, with the main causative agent purported to be aristolochic acid. Urothelial neoplasms develop in approximately $40 \%$ of patients with this nephropathy.

In certain regions of Taiwan where "blackfoot disease," a peripheral vascular disease due to sustained exposure to arsenic, is endemic, there is an unusually high incidence of renal pelvic and ureteral urothelial neoplasms. The cause is postulated to be related to the ingestion of compounds in well water.

In certain regions, urothelial neoplasms arise in women slightly more often than in men and account for approximately $10 \%$ and $40 \%$ of all urothelial carcinomas and renal carcinomas, respectively.

Certain syndromes, including hereditary nonpolyposis colorectal carcinoma (Lynch type II syndrome) and Muir-Torre syndrome, may also be associated with an increased risk for developing urothelial neoplasms of the upper tract.

\author{
ITable 1 I \\ Classification of Urothelial Neoplasms of the Kidney \\ and Ureter* \\ Papillary neoplasms \\ Inverted papilloma ${ }^{\dagger}$ \\ Papilloma \\ Papillary urothelial neoplasm of low malignant potential \\ Papillary urothelial carcinoma \\ Low-grade \\ High-grade \\ "Flat" lesions \\ Urothelial dysplasia \\ In situ urothelial carcinoma \\ Invasive urothelial carcinoma \\ Conventional \\ With aberrant differentiation (squamous, glandular, \\ small cell/neuroendocrine) \\ Spindle cell carcinoma (sarcomatoid carcinoma) \\ Carcinosarcoma \\ Other ${ }^{\ddagger}$ \\ * Extrapolated from Epstein et al. ${ }^{18}$ \\ ${ }^{\dagger}$ Not truly papillary. \\ ¥ Includes the following variants of urothelial carcinoma: nested, micropapillary, \\ microcystic, lymphoepithelial, and plasmacytoid.
}

\section{Manifestations and Clinical Evaluation}

In the upper tract, urothelial neoplasms may arise at any site lined by urothelium, including the renal papillae, calyces, pelvis, ureteropelvic junction, and ureter.

Patients with upper tract urothelial neoplasms usually seek care because of gross hematuria $(80 \%)$, flank pain $(20 \%)$, and/or a palpable mass $(10 \%)$. $^{7,15,16 .}$

Hydronephrosis or hydroureter may occur secondary to obstruction. Evaluation of the patients consists of a detailed history and physical examination followed by urinalysis, bladder cytology, upper tract radiographic imaging, and cystoscopy. Contrast studies of the upper tract consist of intravenous urograms, computed tomography, and, possibly, retrograde pyelography. Radiologic filling defects found on contrast studies may represent nonneoplastic or neoplastic processes and require confirmation by a cellular or a tissue diagnosis.

Cellular diagnosis begins with bladder cytology, which has a relatively high false-negative rate in cases of upper tract urothelial neoplasms, especially with low-grade tumors. ${ }^{26}$.Brush cytology, which requires ureteral manipulation, anesthesia and fluoroscopic control, has an accuracy of $78 \%{ }^{26}$ 
The most accurate diagnostic modality and one that has been accepted as a standard of care for the evaluation of abnormal filling defects and obstruction is ureteroscopy with tissue biopsy under direct visualization. Streem et al ${ }^{27}$ found that standard evaluation of 12 patients with upper tract urothelial neoplasms, using intravenous urograms, computed tomography, cystoscopy and cytology provided the correct provisional diagnosis in 7 patients. The addition of ureteroscopy increased the number of patients with correct provisional diagnoses to 10 .

\section{Additional Patient and Tumor Characteristics}

Several studies have found that patient age correlates with survival, and women may have a worse outcome.

Patients with upper tract urothelial neoplasms have a high rate of multifocal tumor and tumor recurrence. In a review by Charbit et $\mathrm{al}^{24}$ multifocal disease was present in $30 \%$ of patients with clinically identified solitary lesions who underwent radical surgery.

From $7 \%$ to $58.5 \%$ of patients with upper tract disease have urothelial neoplasms elsewhere, before, concomitant to, or after the renal or ureteral tumor, ${ }^{2,3,5,6,9,10,12,23,24}$ and in a significant proportion of patients (5\%-56\%), bladder carcinoma develops after an upper tract tumor. $6,10,20,21,23$

In contrast, only $4 \%$ of patients with bladder cancer develop upper tract disease (the percentage does not include those with involvement of the distal ureter at cystectomy). ${ }^{15}$

In general, the presence of multiple urothelial neoplasms and tumor shape are considered to be prognostic indicators, ${ }^{2,6,11,23}$, although a few reports have not found these features to be significant predictors of survival in upper tract disease. $^{25}$

The presence of vascular invasion is an adverse predictor of survival and usually is associated with high-grade and high-stage disease.
As expected, vascular invasion and high tumor grade and stage have been shown to correlate with metastases.

The most common sites for metastasis in patients with upper tract urothelial neoplasms are regional lymph nodes, lungs, liver, and bone. ${ }^{10,11,15,17,25 .}$

A multivariate analysis of 109 patients with upper tract urothelial neoplasms by Okikawa et al demonstrated that lymph node status was an independent predictor of survival.

\section{Conclusion}

Urothelial carcinoma of ureter is extremely rare malignancy with typical presentation with haematuria, flank pain or as a mass. Here is a rare presentation of poorly differentiated urothelial carcinoma presenting with bulbar weakness with no prior typical symptoms of the disease.

\section{References}

1. Bloom NA, Vidone RA, Lytton B. Primary carcinoma of the ureter: a report of 102 new cases.J Urol.1970;103:590598.

2. Grabstald H, Whitmore WF, Melamed MR. Renal pelvic tumors.JAMA.1971;218:845-854.

3. Wagle DG, Moore RH, Murphy GP. Primary carcinoma of the renal pelvis.Cancer.1974;33:1642-1648.

4. Schmauz R, Cole P. Epidemiology of cancer of the renal pelvis and ureter.J Natl Cancer Inst.1974;52:1431-1434.

5. Say CC, Hori JM. Transitional cell carcinoma of the renal pelvis: experience from 1940 to 1972 and literature review. J Urol.1974;112:438-442.

6. Nocks BN, Heney NM, Daly JJ, et al. Transitional cell carcinoma of the renal pelvis.Urology.1982;14:472-477.

7. Murphy WM, Beckwith JB, Farrow GM.Tumors of the Kidney, Bladder, and Related Urinary Structures . Washington, DC: Armed Forces Institute of Pathology; 
1994: 313-320.Atlas of Tumor Pathology, 3rd Series, Fascicle 11.

8. Greenlee RT, Hill-Harmon MB, Murray T, et al. Cancer statistics, 2001.CA Cancer J Clin.2001;51:15-36.

9. Grace DA, Taylor WN, Taylor JN, et al. Carcinoma of the renal pelvis: a 15 year review.J Urol.1968;98:566-569.

10. Huben RP, Mounzer AM, Murphy GP. Tumor grade and stage as prognostic variables in upper tract urothelial tumors. Cancer. 1988;62:2016-2020.

11. Vahlensieck W, Sommerkamp H. Therapy and prognosis of carcinoma of the renal pelvis.Eur Urol.1989;16:286-290.

12. Guinan P, Vogelzang NJ, Randazzo R. Renal pelvic cancer: a review of 611 patients treated in Illinois 19751985.Urology. 1992;40:393-399.

13. Kim KH, Leiter E, Brendler H. Primary tumors of the ureter. J Urol.1972;107:955958.

14. Cummings KB. Nephroureterectomy: rationale in the management of transitional cell carcinoma of the upper urinary tract.Urol Clin North Am.1980;7:569-578.

15. Melamed MR, Reuter VE. Pathology and staging of urothelial tumors of the kidney and ureter.Urol Clin North Am. 1993;20:333-347.

16. Bonsib SM. Pathology of the renal pelvis and ureter. In: Eble JN, ed.Tumors and Tumor-like Conditions of the Kidneys and Ureters.New York, NY: Churchill Livingstone; 1990:177-202.

17. Bonsib SM, Eble JN. Renal pelvis and ureter. In: Bostwick DG, Eble JN, eds.Urologic Surgical Pathology.St Louis, MO: Mosby-Year Book; 1997:148-165.

18. Epstein JI, Amin MB, Reuter VE. The World Health Organization/International Society of Urological Pathology consensus classification of urothelial (transitional cell) neoplasms of the urinary bladder.Am J Surg Pathol. 1998;22:1435-1448.

19. Murphy DM, Zincke H, Furlow WL. Primary grade 1 transitional cell carcinoma of the renal pelvis and ureter. $\mathbf{J}$ Urol.1980;123:629-631.

20. Murphy DM, Zincke H, Furlow WL. Management of high grade transitional cell cancer of the upper urinary tract.J Urol. 1981;125:25-29.

21. Ozsahin M, Zouhair A, Villa S, et al. Prognostic factors in urothelial renal pelvis and ureter tumours: a multicentre rare cancer network study.Eur J Cancer.1999;35:738-743.

22. Booth CM, Cameron KM, Pugh RCB. Urothelial carcinoma of the kidney and ureter.Br J Urol.1980;52:430-435.

23. Charbit L, Gendreau MC, Mee S. Tumors of the upper urinary tract: 10 years of experience.J Urol.1991;146:1243- 1246.

24. McLaughlin JK, Silverman DT, Hsing AW. Cigarette smoking and cancers of the renal pelvis and ureter.Cancer Res.1992;52:254-257.

25. Batata MA, Whitmore WF, Hilaris BS, et al. Primary carcinoma of the ureter: a prognostic study.Cancer.1975;35:16261632.

26. Guarnizo E, Pavlovich CP, Seiba M, et al. Ureteroscopic biopsy of upper tract urothelial carcinoma: improved diagnostic accuracy and histopathological considerations using a multi-biopsy approach.J Urol.2000;163:52-55.

27. Streem SB, Pontes JE, Novick AC, et al. Ureteropyeloscopy in the evaluation of upper tract filling defects.J Urol.1981;126:383-385. 